Review

\title{
Hyaluronan: Biosynthesis and signaling ${ }^{\text {tr }}$
}

\author{
Davide Vigetti, Eugenia Karousou, Manuela Viola, Sara Deleonibus, Giancarlo De Luca, Alberto Passi *
}

Dipartimento di Scienze Chirurgiche e Morfologiche, Università degli Studi dell'Insubria, Via J.H. Dunant 5, 21100 Varese, Italy

\section{A R T I C L E I N F O}

Article history:

Received 9 November 2013

Received in revised form 30 January 2014

Accepted 1 February 2014

Available online 7 February 2014

\section{Keywords:}

Glycosaminoglycan

Extracellular matrix

AMPK

O-GlcNacylation

Hyaluronan receptor

\begin{abstract}
A B S T R A C T
Background: Hyaluronan is a critical component of extracellular matrix with several different roles. Besides the contribution to the tissue hydration, mechanical properties and correct architecture, hyaluronan plays important biological functions interacting with different molecules and receptors.

Scope of review: The review addresses the control of hyaluronan synthesis highlighting the critical role of hyaluronan synthase 2 in this context as well as discussing the recent findings related to covalent modifications which influence the enzyme activity. Moreover, the interactions with specific receptors and hyaluronan are described focusing on the importance of polymer size in the modulation of hyaluronan signaling.

Major conclusions: Due to its biological effects on cells recently described, it is evident how hyaluronan is to be considered not only a passive component of extracellular matrix but also an actor involved in several scenarios of cell behavior.

General significance: The effects of metabolism on the control of hyaluronan synthesis both in healthy and pathologic conditions are critical and still not completely understood. The hyaluronan capacity to bind several receptors triggering specific pathways may represent a valid target for new approach in several therapeutic strategies. This article is part of a Special Issue entitled Matrix-mediated cell behaviour and properties.
\end{abstract}

(c) 2014 Elsevier B.V. All rights reserved.

\section{Introduction}

Extracellular matrix (ECM) is a complex network of macromolecules that surrounds cells not only to mechanically support cells and tissue structure, but also to control nutrient and waste exchanges, cell-cell and cell-matrix interactions, and signaling molecular diffusion. Thus, ECM is critical to regulate cell behavior and increasing body of evidences supports the ECM involvement in both physiological as well as pathological processes. The cell microenvironment has a pivotal role in several pathologies as tumors and cardiovascular diseases, in which alterations of cell functions can be exacerbated by external stimuli and altered ECM composition [1-4].

Glycosaminoglycans (GAGs) differ from the other ECM components as they are complex polysaccharides which can carry many chemical possible modifications (i.e., sulfation, acetylation and epimerization) and are covalently linked to a core protein forming proteoglycans (PGs). Such variability permits to these macromolecules to finely modulate protein-protein interactions, enzymatic activity or diffusion of signalling molecules.

Hyaluronan is an atypical and relatively simple GAG, in fact it is an unsulfated and unbranched polysaccharide not linked to any PG core proteins. Hyaluronan is ubiquitously expressed in the ECM of mammals and is composed D-glucuronic acid

\footnotetext{
is This article is part of a Special Issue entitled Matrix-mediated cell behaviour and properties.

* Corresponding author. Tel.: + 390332 397142; fax: + 390332397119

E-mail address: alberto.passi@uninsubria.it (A. Passi).
}

(GlcUA) and N-acetyl-D-glucosamine (GlcNAc) bound together through $\beta 1,3$ and $\beta 1,4$ glycosidic bonds, respectively [5]. This disaccharide moiety is repeated thousands of times generating a linear polymer with a molecular mass ranging from $5 \times 10^{5}$ to $4-5 \times 10^{6} \mathrm{Da}$ and more. Due to its hydrophilic properties, hyaluronan is very hydrated causing the ECM an ideal environment in which cells can move and proliferate. Hyaluronan is an important space filling molecule as it is evident in humor vitreous, derma and at joint level. Besides its molecular sieving properties related to the chemical and bio-mechanical characteristics of hyaluronan, this polymer interacting with specific proteins called hyaladerins, such as TSG6, and membrane receptors like CD44, RHAMM, HARE and toll like receptor (TLR) 4/2, modulates the development, the morphogenesis, the tumorigenesis, the migration, the apoptosis, the cell survival and the inflammation [6-9]. This review focuses on hyaluronan biosynthesis regulation and signaling. On these bases the knowledge of how hyaluronan is produced by the cells and how its metabolism is regulated is of great interest. Growing mass of data related to the control of hyaluronan synthesis is reported in literature in various models and pathologies, and these aspects will be discussed in this work.

\section{Hyaluronan synthesis regulation}

Although the relatively simple structure, hyaluronan possesses many physiological roles. Surprisingly, hyaluronan appeared late during evolution and can be typically found from chordates. Interestingly, some pathogenic bacteria acquired the capability of synthesize hyaluronan that use as a mimetic shield against the host immune system. How bacteria acquired the ability to synthesize hyaluronan is still 
debated, but Streptococcus bacteria need three different genes to produce hyaluronan capsule. Interestingly these three genes, which encode UDP-Glucose pyrophosphorylase (hasC), UDP-Glucose dehydrogenase (hasB) and hyaluronan synthase (hasA), are located in an operon, suggesting the critical role of precursors in hyaluronan biosynthesis [10-12].

In mammals, hyaluronan synthesis occurs on the cellular plasma membrane (contrary to the other GAG synthesis that is in the Golgi apparatus) by means of three hyaluronan synthase isoenzymes (HAS1, 2, and 3) that utilize the uridine diphosphate (UDP) glucuronic acid (UDP-GlcUA) and UDP N-acetylglucosamine (UDP-GlcNAc) as substrates. These two sugar nucleotides have critical functions to regulate hyaluronan synthesis through the modulation of gene expression of HASes and by altering HAS enzymatic activity and stability. UDPGlucose pyrophosphorylase and UDP-Glucose dehydrogenase mediating the synthesis of UDP-glucose and UDP-GlcUA, respectively, have a positive effect on hyaluronan synthesis increasing the availability of one of the HAS substrate $[13,14]$. Whether or not the activity of HAS enzymes during the sorting to the plasma membrane is still unclear, but it seems that these proteins could be functional in endoplasmic reticulum and Golgi [15]. Interestingly, UDP-GlcUA is able to influence the accumulation of HAS2 and 3 transcripts, although the molecular mechanism of such regulation is still not known.

The physiological role of HAS isoenzymes is not yet understood; in vitro HASes have different biochemical properties in terms of size of hyaluronan synthesized and catalytic efficiency [16]. Hyaluronan chain size is critical in many pathophysiological conditions [17,18]. Due to the action of hyaluronidases [19] or the action of oxygen radicals [20], hyaluronan can be fragmented in short oligosaccharides that can trigger inflammation or metalloproteinase activation [21,22]. Alternatively, low molecular weight hyaluronan could be produced by HAS3 [23]. Other mechanisms to alter hyaluronan synthesis can directly involve HAS enzymes by, for instance, post-translational modifications or by alteration of the UDP-sugar pool as already discussed [24,25].

Increased hyaluronan levels are often described in the presence of elevated activities of growth factors and cytokines that are released in rapidly remodeling tissues as during embryonic development and would healing or during certain pathological situations, such as inflammation, tumor progression, and vessel thickening.

Smooth muscle cells (SMCs) have a critical role in cardiovascular pathologies as they strongly contribute to neointima formation. Hyaluronan has pro-atherosclerotic properties controlling SMC proliferation, migration and contributing to immune cell recruitment. Several experiments confirmed this effect by using CD44 knockout animals [26], HAS2 transgenic mice [27], by blocking HA/CD44 interaction or inhibiting hyaluronan synthesis. On these bases, many efforts have been done to study the regulation of hyaluronan synthesis in SMCs. From these studies it is now clear that HAS2, the most abundant and active HAS isoenzymes, has several levels of regulation to coordinate hyaluronan production with the cellular metabolism [28].

Although HASes do not use directly ATP, the synthesis of UDP-GlcUA and UDP-GlcNAc precursors requires ATP, UTP and other critical metabolic molecules as glucose, glutamine, glucosamine and acetyl-CoA, in order to perform the GAG production, an energy consuming process. It is well known that energy charge of the cell has a central role in the integration of the entire metabolism. Although, many enzymes can directly use ATP, ADP and AMP as allosteric modulators, the adenosine monophosphate activated protein kinase (AMPK) has a pivotal role as metabolic sensor and regulator. AMPK is a heterotrimeric protein formed by catalytic $\alpha$ subunit and two regulatory subunits. When the ATP:AMP ratio is high, AMPK is not active, but, when ATP:AMP ratio decreases, the catalytic subunit can be phosphorylated by AMPK upstream kinases triggering AMPK activation. In this active form, AMPK is able to phosphorylate several target proteins that lead to the inhibition of anabolic processes and, in the same time, increasing catabolic pathways with the results to restore ATP levels [29]. AMPK specifically inhibited hyaluronan synthesis without altering other GAGs in human SMC and in mouse embryonic fibroblasts [30]. The reduction of hyaluronan accumulation mediated a decrement of SMC proliferation and migration highlighting as the blocking of hyaluronan can be a new candidate to develop vasoprotective drugs. From a molecular point of view, AMPK phosphorylates HAS2 at threonine 110 (T110); this residue is located on a cytosolic loop of the enzyme which is known to be critical for the enzymatic activity. Interestingly, the action of AMPK could be more complex and tissue specific as in human dermal fibroblasts the activation of AMPK induces HAS2 messenger accumulation [31].

HAS2 can also undergo to the regulation by O-GlcNAcylation. This latter is an intracellular glycosylation mediated by O-GlcNac transferase (OGT) which catalyzes the $\beta$-O-linkage of one residue of $\mathrm{N}$-acetylglucosamine (GlcNAc) to serine or threonine of proteins [32]. The donor of GlcNAc is UDP-GlcNAc, which is synthesized by the hexosamine biosynthetic pathway (HBP) (Fig. 1). HBP is now considered one of the main nutrient sensor as, not only is able to directly recognize the availability of glucose (the more glucose, the more flux though the HBP), but the synthesis of UDP-GlcNAc depends on the metabolism of fatty acids, amino acids, and nucleotides. The pathological relevance of HBP is well known in diabetes, in fact the hyperglycemic condition leads to an increase of UDP-GlcNAc that, in turn, leads to an increase of O-GlcNAcylation [33]. High blood glucose is the cause of diabetic complications (i.e., angiopathies, neuropathies, nephropathies, and retinopathies) which can dramatically affect the patient's lifestyle. However, which molecular mechanisms modified by the excess of glucose are still debated, but O-GlcNAcylation seems to have a central role. Hyaluronan accumulates in the aortas of diabetic subjects [34] and in hyperglycemic animal models hyaluronan increased in vessels [35]. HAS2 can be modified by O-GlcNAc at serine 221 (S221) and such glycosylation induced a great stability of the enzyme in cellular plasma membrane inducing an enhanced hyaluronan synthesis [36]. HAS2 is rapidly degraded by the $26 \mathrm{~S}$ proteasome and O-GlcNAcylation prevented HAS2 degradation. The molecular mechanism of such protection against proteasomal digestion is not understood although it is known that O-GlcNAcylation can directly affect proteasomal activity and ubiquitination. Interestingly, HAS2 can form dimers or oligomers and is subjected to regulatory ubiquitination i.e. is mono-ubiquitinated at lysine residue 190 (K190) which has a key role for its activity and dimerization [37] (Fig. 2A).

HAS2 represents the main hyaluronan synthetic enzyme in adult cells and is reasonable that its activity is finely regulated. On the other hand, HAS1 and HAS3 seem to have peculiar roles even if not completely clarified. HAS1 seems to be important in hyperglycemic conditions having a low affinity for hyaluronan precursors, whereas HAS3 is involved in the formation of particular microvilli structures [38,39]. Although HAS3 has been described to be phosphorylable when over expressed in cells, the effects of AMPK and O-GlcNAcylation are specific for HAS2 [30,36]. Interestingly, ERK increased the activity of all the three HASes indicating that protein phosphorylation in residues different from that modified by AMPK, can lead to hyaluronan accumulation [40]. The regulation of HASes is also at transcriptional level, as previously reviewed [41] and, recently, HAS2 and 3 have been demonstrated to be similarly upregulated by oxidized LDL and 22-oxysterol which is the agonist of Liver X Receptor agonist [42]. Although not deeply investigated in mammals, bacterial HASes need a particular lipid microenvironment (i.e., cardiolipin) [43] and, thus, eukaryotic HASes could have another point of regulation through lipid metabolism and/or the presence of lipid rafts.

Interestingly, the genomic locus of HAS2 can generate a natural antisense transcript (NAT) of HAS2, named HAS2-AS1 and exon 2 of HAS2-AS1 NAT is complemental to exon 1 of HAS2 mRNA. Although several years ago HAS2-AS1 was described that the overexpression of HAS2-AS1 decreased HAS2 mRNA [44], recently it has been described that HAS2-AS1-HAS2 duplex at RNA level stabilized HAS2 messenger leading to HAS2 accumulation [45] (Fig. 2B). 


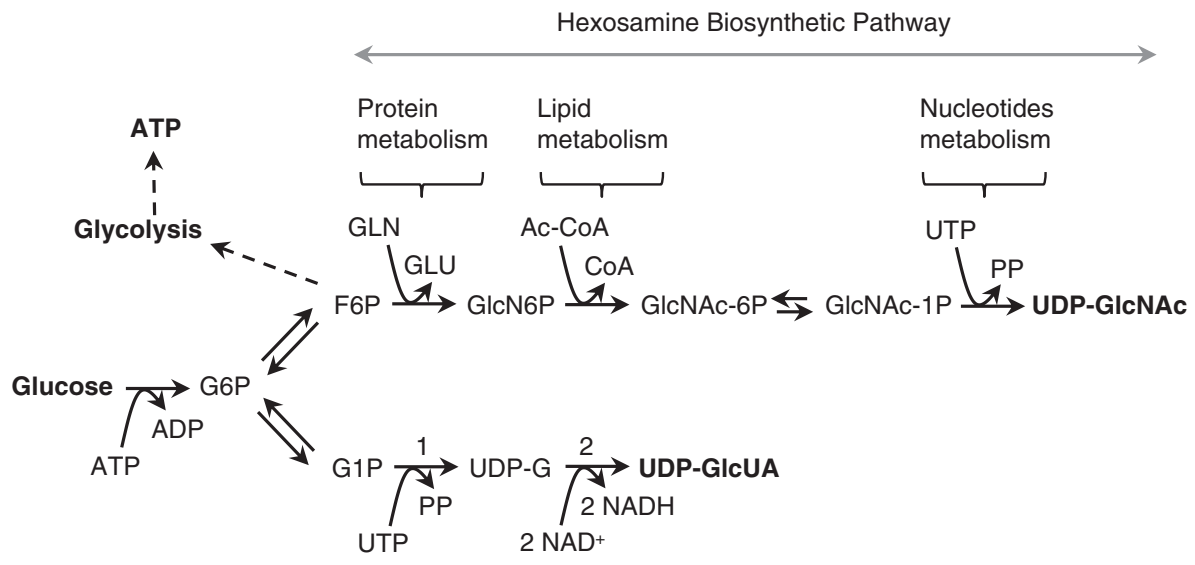

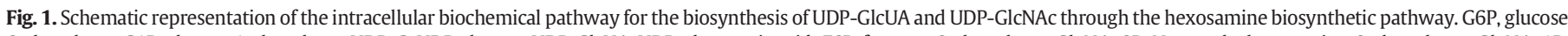

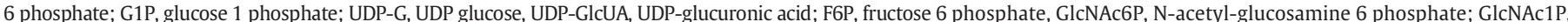

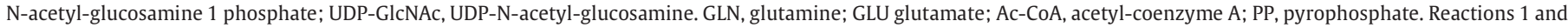
2 are catalyzed by UDP-Glucose pyrophosphorylase and UDP-Glucose dehydrogenase, respectively.

\section{HA signaling}

Despite its simple structure, hyaluronan has several interacting properties with numerous proteins including matrix components and cell membrane receptors (Fig. 3). It was reported that hyaluronan can strongly interact with leukocytes throughout receptor CD44 contributing to the retention of these cells in inflammation site $[46,47]$. The hyaluronan capacity to interact with cell receptors triggers several cell responses that are specific for the cell types demonstrating that this polymer possesses a strong capacity to modulate cell behavior
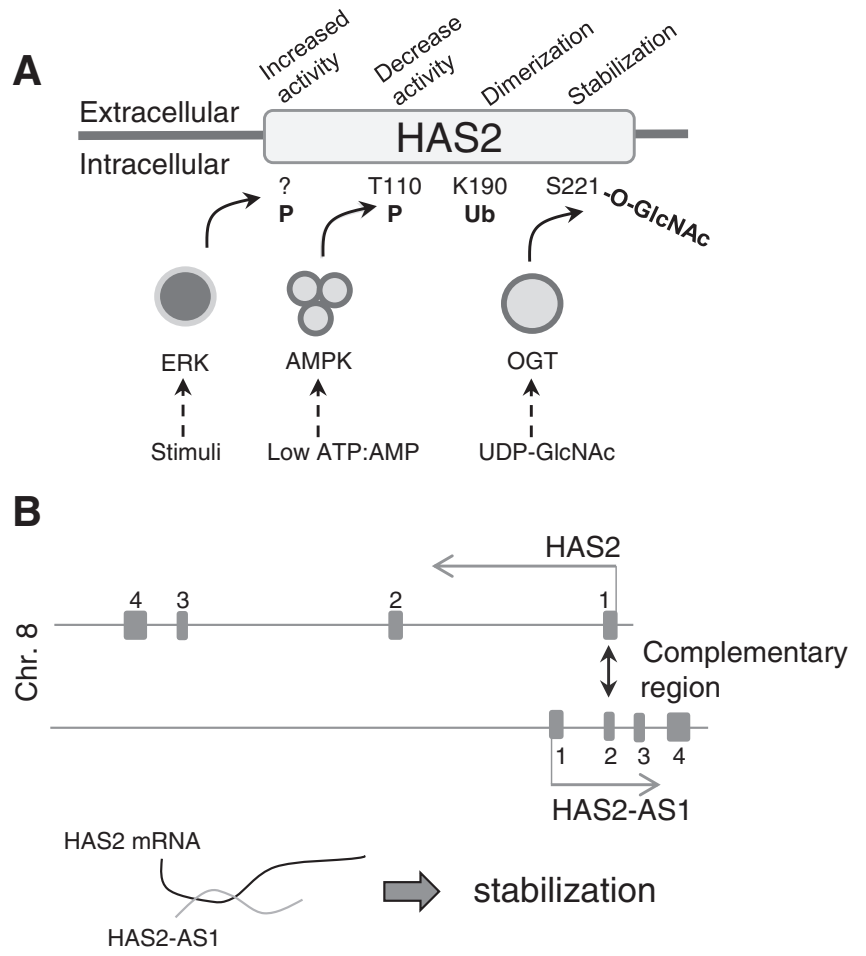

Fig. 2. A. Schematic representation of the covalent modifications on HAS2 protein which modulate enzymatic activity. T, Threonine; K, lysine; S, serine; P, phosphate group; Ub, mono-ubiquitination; OGT, O-GlcNAc transferase. B. Scheme of HAS2 locus on chromosome 8 and possible mechanism of the natural antisense transcript HAS2-AS1 in HAS2 mRNA stabilization. participating to different cell activities including proliferation, migration, and inflammation in normal tissues and in organ pathology. The most important aspect of hyaluronan signaling is the size. In fact the hyaluronan size has specific importance in this context, it was demonstrated that hyaluronan with different sizes can induce different signaling pathways. These aspects were initially described in CD44 signaling pathway [48] and then in TLR4 and 2 [49,50]. The hyaluronan is therefore able to interact with various receptors as large molecule with several million Daltons (high molecular weight - HMW) as well as low molecular weight (LMW). The effects of these polymers with different molecular weight are markedly different triggering different signaling pathways including NF- $\kappa B$ and ERK phosphorylation [51]. The hypothesis proposed so far is the capacity of HMW to cluster the receptors on cell membrane, modulating in this way the receptor activity [49]. If LMW hyaluronan interacts with the receptors on cell membrane it is unable to gather the proteins on the cell membrane and the signaling differs strongly from that induced by HMW on the same cells. Fragmentation of hyaluronan is therefore a critical aspect in the hyaluronan signaling capacity. Usually the hyaluronan catabolism is catalyzed by hyaluronidases, which are hydrolases and include six enzymes in mammals (Hyal-1, -2, -3, -4, P1 and PH20) [52]. Hyal-1 and -2 are able to produce fragments with different sizes working sequentially, Hyal-2 degrades hyaluronan in fragments of up $20 \mathrm{kDa}$ whereas Hyal-1 reduced them to up $800 \mathrm{Da}$. Moreover, free radicals are also responsible for hyaluronan fragmentation during tissue injuries [53,54]. The hyaluronan fragments are usually internalized by the cells throughout CD44 receptor, but in the presence of free radical production or in excess of oligomers, as in inflammation or in certain tumors where the hyaluronidase activity is high, hyaluronan fragments remain in the cell microenvironment free to interact with hyaluronan receptors. It was therefore critical the minimal size of hyaluronan able to trigger the cell response. The active hyaluronan size may range from 4 to 6 disaccharides units (4-6 mers), and they are able to induce NF- $\kappa$ B signaling and metalloprotease production [55,56], whereas oligosaccharides with size from 4 to 16 mers are able to induce inflammatory responses in dendritic cells [50,57-59]. Considering the critical role of inflammation in cancer microenvironment [60], the function of hyaluronan with high or low molecular weight is obviously critical in cancer progression $[61,62]$. The role of hyaluronan fragments in inflammation was described in several cell and animal models $[63,64]$, whereas the intact hyaluronan protects tissue damage [65].

The biological effects of HMW and LMW are due to the different activities of the receptor; for instance, HMW hyaluronan (>1000 kDa) 


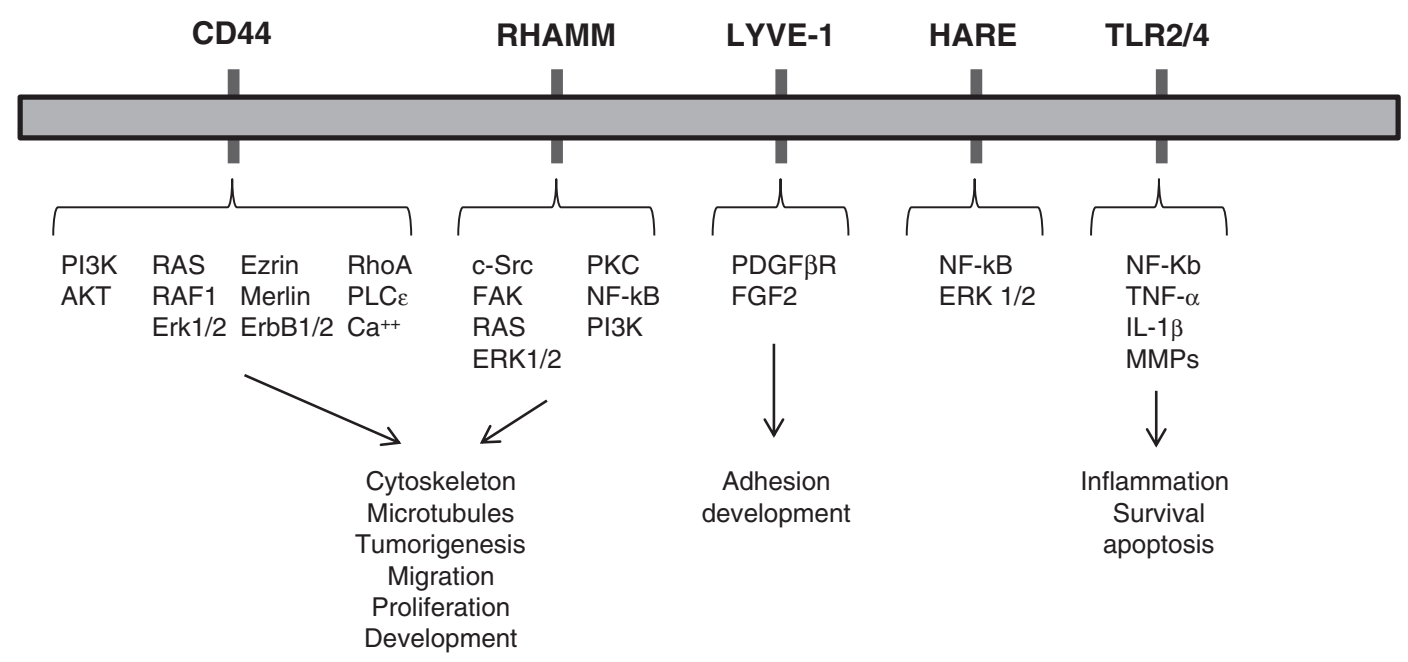

Fig. 3. Schematic representation of the signaling cascade of hyaluronan receptors and their involvement in cell and tissue functions.

is antiangiogenic [66] whereas the fragments ranging from 3 to 25 disaccharides are strongly pro-angiogenic in human cell model [67], all these cell behaviors are triggered by CD44 and RHAMM receptors.

\section{1. $C D 44$}

Among the receptors involved in hyaluronan signaling, the CD44 is the most common on cell membranes and it is present in almost all human cells $[68,69]$. CD44 is a type I transmembrane protein existing in at least 10 different splicing variants encoding for its extracellular domain and different grades of glycosylation [70]. CD44 is a glycoprotein or a part-time proteoglycan and its sulfated glycosaminoglycan chains (chondroitin or heparan sulfate) can interact with different growth factors as well as cytokines and extracellular matrix proteins as fibronectin [69]. Its role in this context is mainly due to its capacity to work as docking agent for MMP9 or as growth factor reservoir. One of the specific function of CD44 is the capacity to bind and internalize HA. The most common form in mammals is the standard form of CD44 with a molecular mass of $85 \mathrm{kDa}$. The cytoplasmic domain is highly conserved and could be phosphorylated to transduce the signal when the ligand binds the extracellular domain. The CD44 signaling cascade is critical for BMP-7 stimulation, involving SMAD1-4 phosphorylation before their nuclear translocation, and all these signaling processes require a hyaluronan binding on CD44 [71]. Besides the role of CD44 in cell adhesiveness, the phosphorylation of cytoplasmic CD44 domain is critical for cell migration and infiltration, as demonstrated in melanoma model [72], confirming the pivotal role of the HA-CD44 interaction in cancer cell migration. It is noteworthy that CD44 is highly expressed on cancer cell membranes and its capacity to interact with cytoskeleton explains its ability to promote cell motility. Moreover, CD44 in fibroblasts is responsible for cell migrations into the fibrotic area contributing to matrix alterations [73].

The signaling cascade triggered by CD44 includes PI3K/PDK1/Akt activity as well as Ras phosphorylation cascade involving RAF1, MEK and ERK1/2. It is demonstrated that the inhibition of ERK1/2 phosphorylation abrogates the CD44 dependent motility during cell aging [74].

Ezrin, merlin and erbB1,2 are involved in CD44 cytoplasmic signaling forming a complex with CD44 cytosolic domain with Hsp90 [62]. The complexity of hyaluronan signaling through CD44, for example the hyaluronan-CD44 interactions with leukemia-associated RhoGEF and epidermal growth factor receptor promote Rho/Ras co-activation and phospholipase C epsilon-Ca2 + signaling, was well described [75].

The role of hyaluronan on PDGF-BB receptor activity was reported, showing that in the presence of hyaluronan CD44 is able to interact with PDGF-BB receptor forming a complex on the cell membrane preventing PDGF-BB receptor activation. This effect is mediated by the activity of a tyrosine phosphatase to the receptor [76]. The role of CD44 hyaluronan complexes in keratinocytes from mice bearing an antisense CD44 transgene was used to investigate its effect on cell proliferation in response to specific skin stimuli [77].

During lung inflammation the critical role of CD44 in controlling the inflammatory process was demonstrated [78]. The CD44 is therefore involved in the control of exaggerated inflammatory response downregulating the signal of TLR4 [79]. The role of hyaluronan in inflammation development is also demonstrated by the data reported in an animal model where animal lungs were protected from LPS inflammation damage by an aerosol pre-treatment with HMW hyaluronan [80].

CD44 signaling is critical in wound healing, where CD44 on fibroblasts is critical for their migration in wounded area from perilesional stroma [81]. It is noteworthy that CD44 per se is not able to induce cell migration but only the interaction between HMW hyaluronan and CD44 can induce cell migration and promote the wound healing process [82]. Moreover, the directionality of cell migration is strongly dependent on CD44 expression and on hyaluronan gradient in extracellular matrix environment [83].

\subsection{RHAMM}

RHAMM receptor takes its name from the acronym Receptor for Hyaluronan Mediated Motility and it is also known as CD168. RHAMM was described in tumor cell line $[84,85]$ and in several cell types including endothelial cells [86]. Several RHAMM isoforms are produced by alternative splicing, and these transcript variants produce proteins with a variable distribution such as on the cell surface, within the cytoplasm, in the nucleus, or secreted extracellularly [87]. Intracellular RHAMM can interact with actin filaments, the centrosome, microtubules, and the mitotic spindle [88]. Moreover, it could be considered a scaffold protein modulating the formation of extracellular signalregulated kinase 2 (ERK2), MEK1, and ERK1,2 complexes and controlling activation and targeting of ERK1,2 to specific substrates [89].

Hyaluronan-RHAMM interaction can trigger several cellular signaling cascades probably working as a co-receptor for integral membrane proteins [88]. These signaling molecules include Ras, focal adhesion kinase (FAK), ERK1/2, protein kinase C (PKC), tyrosine kinase pp60 (c-Src), NF- $\kappa$ B, and phosphatidylinositol kinase (PI3K) [90,91].

RHAMM signaling seems to involve in some case Ras-oncogene activity [92] but in other models the pathway seems different [93]. RHAMM defective cells showed a reduced ERK1/2 phosphorylation and migration properties, indicating that signaling of RHAMM involves 
this phosphorylation cascade [94]. Interestingly, RHAMM abrogation influenced CD44 localization on the plasma membrane and signaling [94].

The interactions between hyaluronan and RHAMM play an important role in tissue repair and inflammation [95]. In smooth muscle cell cultures was demonstrated that the abrogation of hyaluronanmediated RHAMM signaling alters the cell migration and therefore their capacity to heal tissue lesions. In macrophages the role of RHAMM is also critical in the cell activation during the hyaluronan incubation [95]. In fibromatosis RHAMM is highly expressed and in the fibroblasts RHAMM stimulates their proliferation in vitro [96]. Conversely, the RHAMM abrogation in fibroblasts reduced their healing properties and migration capacity [94].

\subsection{HARE}

HARE takes its name from the acronym Hyaluronan Receptor for Endocytosis and it is a $190 \mathrm{kDa}$ polypeptide generated by the proteolytic cleavage of stabilin 2 or FEEL2 [97]. This hyaluronan receptor was initially isolated from sinusoidal endothelial cells in the liver, lymph nodes and spleen [98], but its expression reflects the stage of development in the organs [99]. HARE protein is described in the endothelial cells in the liver, spleen and lymph nodes, it is also described in endothelial cells from different tissues, including the eye, brain, kidney and heart. The HARE structure is quite complex, including several hyaluronan binding motifs $(\mathrm{B}(\mathrm{X} 7) \mathrm{B})$, fasciclin like binding domains and 18-20 EGF domains [100]. Interestingly, HARE can bind not only HA, but also other chondroitin sulfate (CSA, C, D and E) with exception of heparin, heparin sulfate and keratan sulfate [97,101]. HARE functions are related to the hyaluronan endocytosis and this receptor is co-localized on cell membrane of endothelial cells with clathrin, but then, during the endocytosis process, HARE is not co-localized with internalized hyaluronan during its way to lysosomes [102]. HARE is therefore not only specific for hyaluronan only, but it is also able to recognize other GAGs. These aspects reflect the role of HARE in the clearance of the GAGs from circulation.

The interaction of HARE with hyaluronan of low molecular mass (i.e., $80 \mathrm{kDa}$ ) is able to induce ERK1/2 activation whereas the uptake of 40-400-kDa, but not larger or smaller, hyaluronan stimulated NF- $\kappa B$ activation [103]. However, it is still unclear whether hyaluronan endocytosis is required for HARE-mediated cell signaling and whether $\mathrm{NF}-\kappa \mathrm{B}$ and ERK activations are linked.

\subsection{LYVE 1}

LYVE 1 takes its name from the acronym Lymphatic Vessel Endothelial hyaluronan receptor 1, also known as CRSBP1 that is for Cell Surface Retention Sequence Binding Protein-1. It was described in human lymphatic system and then in mice [104,105]. LYVE 1 is a type I integral membrane glycoprotein with a strong homology with CD44. Even if the LYVE 1 expression is typically related to the lymphatic system, LYVE1 receptors were also detected in sinusoidal endothelial cells in the liver [106] and reticular cell of the lymph nodes [107].

Due to its abundant presence in lymphatic endothelial cells, LYVE 1 was used as specific marker to detect lymphatics [108], but it is also important in the prognostic assessment in head and neck squamous cell carcinomas [109]. The internalization of LYVE 1 and its digestion in lysosomes is strongly dependent on the hyaluronan binding [110]. LYVE 1 works to absorb the hyaluronan from tissue to the lymph, regulating therefore the tissue hydration and its biomechanical properties [105]. It is important to note that the expression of LYVE 1 was also reported in macrophages [111]. Despite the critical role of the content control of the amount of hyaluronan in the tissues, the abrogation of LYVE 1 did not generate abnormal animals, indicating that other receptors are probably present in the lymphatics able to rescue the LYVE 1 abrogation [112]. From these experiments it is evident that the role of LYVE 1 is mainly related to the hyaluronan content control in tissues and it has no role in the trafficking of dendritic cells and other leukocytes in lymph nodes, indicating that ICAM-1 and VCAM- 1 are likely more important in these processes [113].

Although the critical role of LYVE 1 in hyaluronan turnover, which intracellular pathways are regulated by this receptor remains largely unknown. LYVE 1 can form complex with fibroblast growth factor-2 and this interaction could inhibit fibroblast growth factor- 2 induced lymphangiogenesis [114]. CRSBP 1/LYVE 1 interacting with PDGFßR$\beta$-catenin complex, resulting in tyrosine phosphorylation of the complex, dissociation of $\beta$-catenin and p120-catenin from VE-cadherin, and internalization of VE-cadherin with the consequence of disruption of VE-cadherin-mediated intercellular adhesion and opening of intercellular junctions in lymphatic endothelial cell monolayers [115].

\subsection{Toll like receptors}

Toll like receptors (TLRs) are able to initiate the innate immune response, which represents the first defense against pathogens. The TLR activation is a very rapid process, even if without the specificity of the adaptive response $[116,117]$. TLR4 is a transmembrane receptor able to recognize LPS molecules, whereas TLR2 is able to recognize mycobacteria and gram positive bacteria [118]. After interaction with hyaluronan oligosaccharides, the macrophages are able to activate chemokine genes, and this effect is strongly dependent on MyD88 presence [49]. The abrogation of TLR2 and 4 as well as MyD88 abolished completely the activation of chemokines in macrophages in in vitro model [49]. Moreover, the treatment of dendritic cells with hyaluronan oligosaccharides induced cell maturation throughout the phosphorylation cascade of MAPK and nuclear translocation of NF- $\kappa B$ and eventually the production of TNF-alpha. The role of hyaluronan fragments in innate immune response is also demonstrated by the findings in the skin transplant rejection, where an increase of hyaluronan fragments is described, suggesting a role of hyaluronan oligosaccharides in alloimmunity [119]. Moreover, the HMW hyaluronan is able to induce the expression of IL-1R-associated kinase-M, which is a negative regulator of TLR signaling. This phenomenon of deactivation is described in human monocytes and the role of CD44 and TLR4 is experimentally established [120]. The expression of MMP2 and IL8 is also stimulated by hyaluronan fragments in part by the signaling of TLR4 [56]. HMW hyaluronan is also able to inhibit the osteoclast differentiation by TLR4 signaling, interfering with the signal triggered by macrophage colony-stimulating factor (M-CSF) [121]. These effects of hyaluronan on osteoclasts using TLR4 signaling highlight the possibility that besides CD44, the hyaluronan interaction with receptor TLRs plays a critical role not only in the innate immune response but also in tissue metabolism. As reported for the gut, the interaction between hyaluronan and TLR may be considered a key element for tissue homeostasis [122] triggering the synthesis of a class of proteins (defesins), which have not only strong antibacterial properties but also exert a strong regenerative stimulus for different cells [123]. The effects of LMW hyaluronan are triggered by TLR4 and the signaling depends on the activation of NF- $\kappa$ B pathway.

\section{Conclusion and perspectives}

An emerging body of literature highlights the role of hyaluronan in several biological processes in different cell types and tissues, both in normal condition and pathology. These observations suggest that HA, besides its critical role as structural component of extracellular matrix, has pivotal roles in tissue metabolism. Several receptors are described in all tissues with capacity to interact with hyaluronan and the signaling pathways triggered by these receptors can control different genes including chemokines and in the same time alters the cytoskeleton interactions with cytoplasmic receptor domains. Moreover, the effects of hyaluronan are strongly dependent on the molecular size, indicating that polymer with a molecular weight of $>1000 \mathrm{kDa}$ can play roles 
inducing a clustering of receptor on cell membrane with an antiapoptotic activity. Fragments of hyaluronan with a mass of $<200 \mathrm{kDa}$ can exert an opposite effect, with a strong pro-inflammatory stimulus which was described in inflammatory cells and macrophages. It is an intriguing aspect that the hyaluronan in epithelial cells can induce a signaling influencing the synthesis of specific proteins involved not only in the bacterial growth control but also in tissue regeneration and repair. From this point of view the studies on hyaluronan signaling and hyaluronan metabolism may represent a new target for an innovative strategy in tissue repair and in the inflammation control.

\section{References}

[1] H. Acloque, M.S. Adams, K. Fishwick, M. Bronner-Fraser, M.A. Nieto, Epithelialmesenchymal transitions: the importance of changing cell state in development and disease, J. Clin. Invest. 119 (2009) 1438-1449.

[2] K. Akita, A. von Holst, Y. Furukawa, T. Mikami, K. Sugahara, A. Faissner, Expression of multiple chondroitin/dermatan sulfotransferases in the neurogenic regions of the embryonic and adult central nervous system implies that complex chondroitin sulfates have a role in neural stem cell maintenance, Stem Cells 26 (2008) 798-809.

[3] D. Vigetti, P. Moretto, M. Viola, A. Genasetti, M. Rizzi, E. Karousou, F. Pallotti, G. De Luca, A. Passi, Matrix metalloproteinase 2 and tissue inhibitors of metalloproteinases regulate human aortic smooth muscle cell migration during in vitro aging, Faseb J. 20 (2006) 1118-1130

[4] D. Vigetti, M. Gotte, M.S. Pavao, A.D. Theocharis, Cellular microenvironment in human pathologies, Biomed. Res. Int. 2013 (2013) 946958.

[5] J.A. McDonald, T.D. Camenisch, Hyaluronan: genetic insights into the complex biology of a simple polysaccharide, Glycoconj. J. 19 (2002) 331-339.

[6] A.J. Day, G.D. Prestwich, Hyaluronan-binding proteins: tying up the giant, J. Biol. Chem. 277 (2002) 4585-4588.

[7] D. Vigetti, A. Genasetti, E. Karousou, M. Viola, P. Moretto, M. Clerici, S. Deleonibus, G. De Luca, V.C. Hascall, A. Passi, Proinflammatory cytokines induce hyaluronan synthesis and monocyte adhesion in human endothelial cells through hyaluronan synthase 2 (HAS2) and the nuclear factor-kappaB (NF-kappaB) pathway, J. Biol. Chem. 285 (2011) 24639-24645.

[8] D. Vigetti, M. Rizzi, P. Moretto, S. Deleonibus, J.M. Dreyfuss, E. Karousou, M. Viola, M. Clerici, V.C. Hascall, M.F. Ramoni, G. De Luca, A. Passi, Glycosaminoglycans and glucose prevent apoptosis in 4-methylumbelliferone-treated human aortic smooth muscle cells, J. Biol. Chem. 286 (2011) 34497-34503.

[9] D. Vigetti, M. Rizzi, M. Viola, E. Karousou, A. Genasetti, M. Clerici, B. Bartolini, V.C. Hascall, G. De Luca, A. Passi, The effects of 4-methylumbelliferone on hyaluronan synthesis, MMP2 activity, proliferation, and motility of human aortic smooth muscle cells, Glycobiology 19 (2009) 537-546.

[10] P.H. Weigel, P.L. DeAngelis, Hyaluronan synthases: a decade-plus of novel glycosyltransferases, J. Biol. Chem. 282 (2007) 36777-36781.

[11] P.H. Weigel, V.C. Hascall, M. Tammi, Hyaluronan synthases, J. Biol. Chem. 272 (1997) 13997-14000.

[12] P.H. Weigel, A.J. Padgett-McCue, B.A. Baggenstoss, Methods for measuring Class I membrane-bound hyaluronan synthase activity, Methods Mol. Biol. 1022 (2013) 229-247.

[13] C. Magee, M. Nurminskaya, T.F. Linsenmayer, UDP-glucose pyrophosphorylase: up-regulation in hypertrophic cartilage and role in hyaluronan synthesis, Biochem. J. 360 (2001) 667-674.

[14] D. Vigetti, M. Ori, M. Viola, A. Genasetti, E. Karousou, M. Rizzi, F. Pallotti, I. Nardi, V.C. Hascall, G. De Luca, A. Passi, Molecular cloning and characterization of UDP-glucose dehydrogenase from the amphibian Xenopus laevis and its involvement in hyaluronan synthesis, J. Biol. Chem. 281 (2006) 8254-8263.

[15] D. Vigetti, A. Genasetti, E. Karousou, M. Viola, M. Clerici, B. Bartolini, P. Moretto, G. De Luca, V.C. Hascall, A. Passi, Modulation of hyaluronan synthase activity in cellular membrane fractions, J. Biol. Chem. 284 (2009) 30684-30694.

[16] N. Itano, T. Sawai, M. Yoshida, P. Lenas, Y. Yamada, M. Imagawa, T. Shinomura, M. Hamaguchi, Y. Yoshida, Y. Ohnuki, S. Miyauchi, A.P. Spicer, J.A. McDonald, K. Kimata, Three isoforms of mammalian hyaluronan synthases have distinct enzymatic properties, J. Biol. Chem. 274 (1999) 25085-25092.

[17] D. Jiang, J. Liang, P.W. Noble, Hyaluronan in tissue injury and repair, Annu. Rev. Cell Dev. Biol. 23 (2007) 435-461.

[18] D. Jiang, J. Liang, P.W. Noble, Hyaluronan as an immune regulator in human diseases, Physiol. Rev. 91 (2011) 221-264.

[19] R. Stern, Hyaluronidases in cancer biology, Semin. Cancer Biol. 18 (2008) 275-280.

[20] R.A. Greenwald, W.W. Moy, Effect of oxygen-derived free radicals on hyaluronic acid, Arthritis Rheum. 23 (1980) 455-463.

[21] M.R. Horton, S. Shapiro, C. Bao, C.J. Lowenstein, P.W. Noble, Induction and regulation of macrophage metalloelastase by hyaluronan fragments in mouse macrophages, J. Immunol. 162 (1999) 4171-4176.

[22] S. Ohno, H.J. Im, C.B. Knudson, W. Knudson, Hyaluronan oligosaccharides induce matrix metalloproteinase 13 via transcriptional activation of NFkappaB and p38 MAP kinase in articular chondrocytes, J. Biol. Chem. 281 (2006) 17952-17960.

[23] K.J. Bai, A.P. Spicer, M.M. Mascarenhas, L. Yu, C.D. Ochoa, H.G. Garg, D.A. Quinn, The role of hyaluronan synthase 3 in ventilator-induced lung injury, Am. J. Respir. Crit. Care Med. 172 (2005) 92-98.
[24] P.L. DeAngelis, Monodisperse hyaluronan polymers: synthesis and potential applications, Curr. Pharm. Biotechnol. 9 (2008) 246-248.

[25] W. Jing, P.L. DeAngelis, Synchronized chemoenzymatic synthesis of monodisperse hyaluronan polymers, J. Biol. Chem. 279 (2004) 42345-42349.

[26] C.A. Cuff, D. Kothapalli, I. Azonobi, S. Chun, Y. Zhang, R. Belkin, C. Yeh, A. Secreto, R.K. Assoian, D.J. Rader, E. Pure, The adhesion receptor CD44 promotes atherosclerosis by mediating inflammatory cell recruitment and vascular cell activation, J. Clin. Invest. 108 (2001) 1031-1040.

[27] S. Chai, Q. Chai, C.C. Danielsen, P. Hjorth, J.R. Nyengaard, T. Ledet, Y. Yamaguchi, L.M. Rasmussen, L. Wogensen, Overexpression of hyaluronan in the tunica media promotes the development of atherosclerosis, Circ. Res. 96 (2005) 583-591.

[28] D. Vigetti, M. Viola, E. Karousou, G. De Luca, A. Passi, Metabolic control of hyaluronan synthases, Matrix Biol. (2014) (in press).

[29] M.C. Towler, D.G. Hardie, AMP-activated protein kinase in metabolic control and insulin signaling, Circ. Res. 100 (2007) 328-341.

[30] D. Vigetti, M. Clerici, S. Deleonibus, E. Karousou, M. Viola, P. Moretto, P. Heldin, V.C. Hascall, G. De Luca, A. Passi, Hyaluronan synthesis is inhibited by adenosine monophosphate-activated protein kinase through the regulation of HAS2 activity in human aortic smooth muscle cells, J. Biol. Chem. 286 (2011) 7917-7924.

[31] T. Yamane, K. Kobayashi-Hattori, Y. Oishi, Adiponectin promotes hyaluronan synthesis along with increases in hyaluronan synthase 2 transcripts through an AMP-activated protein kinase/peroxisome proliferator-activated receptor-alphadependent pathway in human dermal fibroblasts, Biochem. Biophys. Res. Commun. 415 (2011) 235-238.

[32] G.W. Hart, M.P. Housley, C. Slawson, Cycling of O-linked beta-N-acetylglucosamine on nucleocytoplasmic proteins, Nature 446 (2007) 1017-1022.

[33] W.B. Dias, G.W. Hart, O-GlcNAc modification in diabetes and Alzheimer's disease, Mol. Biosyst. 3 (2007) 766-772.

[34] L. Heickendorff, T. Ledet, L.M. Rasmussen, Glycosaminoglycans in the human aorta in diabetes mellitus: a study of tunica media from areas with and without atherosclerotic plaque, Diabetologia 37 (1994) 286-292.

[35] T.O. McDonald, R.G. Gerrity, C. Jen, H.J. Chen, K. Wark, T.N. Wight, A. Chait, K.D. O'Brien, Diabetes and arterial extracellular matrix changes in a porcine model of atherosclerosis, J. Histochem. Cytochem. 55 (2007) 1149-1157.

[36] D. Vigetti, S. Deleonibus, P. Moretto, E. Karousou, M. Viola, B. Bartolini, V.C. Hascall, M. Tammi, G. De Luca, A. Passi, Role of UDP-N-acetylglucosamine (GlcNAc) and O-GlcNAcylation of hyaluronan synthase 2 in the control of chondroitin sulfate and hyaluronan synthesis, J. Biol. Chem. 287 (2012) 35544-35555.

[37] E. Karousou, M. Kamiryo, S.S. Skandalis, A. Ruusala, T. Asteriou, A. Passi, H. Yamashita, U. Hellman, C.H. Heldin, P. Heldin, The activity of hyaluronan synthase 2 is regulated by dimerization and ubiquitination, J. Biol. Chem. 285 (2010) 23647-23654.

[38] A. Kultti, K. Rilla, R. Tiihonen, A.P. Spicer, R.H. Tammi, M.I. Tammi, Hyaluronan synthesis induces microvillus-like cell surface protrusions, J. Biol. Chem. 281 (2006) 15821-15828.

[39] K. Rilla, S. Oikari, T.A. Jokela, J.M. Hyttinen, R. Karna, R.H. Tammi, M.I. Tammi, Hyaluronan synthase 1 (HAS1) requires higher cellular UDP-GIcNAc concentration than HAS2 and HAS3, J. Biol. Chem. 288 (2013) 5973-5983.

[40] L.Y. Bourguignon, E. Gilad, K. Peyrollier, Heregulin-mediated ErbB2-ERK signaling activates hyaluronan synthases leading to CD44-dependent ovarian tumor cell growth and migration, J. Biol. Chem. 282 (2007) 19426-19441.

[41] R.H. Tammi, A.G. Passi, K. Rilla, E. Karousou, D. Vigetti, K. Makkonen, M.I. Tammi, Transcriptional and post-translational regulation of hyaluronan synthesis, Febs J. 278 (2011) 1419-1428.

[42] M. Viola, B. Bartolini, D. Vigetti, E. Karousou, P. Moretto, S. Deleonibus, T. Sawamura, T.N. Wight, V.C. Hascall, G. De Luca, A. Passi, Oxidized low density lipoprotein (LDL) affects hyaluronan synthesis in human aortic smooth muscle cells, J. Biol. Chem. 288 (2013) 29595-29603.

[43] V.L. Tlapak-Simmons, E.S. Kempner, B.A. Baggenstoss, P.H. Weigel, The active streptococcal hyaluronan synthases (HASs) contain a single HAS monomer and multiple cardiolipin molecules, J. Biol. Chem. 273 (1998) 26100-26109.

[44] H. Chao, A.P. Spicer, Natural antisense mRNAs to hyaluronan synthase 2 inhibit hyaluronan biosynthesis and cell proliferation, J. Biol. Chem. 280 (2005) 27513-27522.

[45] D.R. Michael, A.O. Phillips, A. Krupa, J. Martin, J.E. Redman, A. Altaher, R.D. Neville, J. Webber, M.Y. Kim, T. Bowen, The human hyaluronan synthase 2 (HAS2) gene and its natural antisense RNA exhibit coordinated expression in the renal proximal tubular epithelial cell, J. Biol. Chem. 286 (2011) 19523-19532.

[46] J. Lesley, R. Hyman, N. English, J.B. Catterall, G.A. Turner, CD44 in inflammation and metastasis, Glycoconj. J. 14 (1997) 611-622.

[47] C. Termeer, J.P. Sleeman, J.C. Simon, Hyaluronan-magic glue for the regulation of the immune response? Trends Immunol. 24 (2003) 112-114.

[48] N. Itano, Simple primary structure, complex turnover regulation and multiple roles of hyaluronan, J. Biochem. 144 (2008) 131-137.

[49] D. Jiang, J. Liang, J. Fan, S. Yu, S. Chen, Y. Luo, G.D. Prestwich, M.M. Mascarenhas, H.G. Garg, D.A. Quinn, R.J. Homer, D.R. Goldstein, R. Bucala, P.J. Lee, R. Medzhitov, P.W. Noble, Regulation of lung injury and repair by Toll-like receptors and hyaluronan, Nat. Med. 11 (2005) 1173-1179.

[50] C. Termeer, F. Benedix, J. Sleeman, C. Fieber, U. Voith, T. Ahrens, K. Miyake, M. Freudenberg, C. Galanos, J.C. Simon, Oligosaccharides of hyaluronan activate dendritic cells via toll-like receptor 4, J. Exp. Med. 195 (2002) 99-111.

[51] R. Stern, A.A. Asari, K.N. Sugahara, Hyaluronan fragments: an information-rich system, Eur. J. Cell Biol. 85 (2006) 699-715.

[52] A.B. Csoka, G.I. Frost, R. Stern, The six hyaluronidase-like genes in the human and mouse genomes, Matrix Biol. 20 (2001) 499-508. 
[53] U.M. Agren, R.H. Tammi, M.I. Tammi, Reactive oxygen species contribute to epidermal hyaluronan catabolism in human skin organ culture, Free Radic. Biol. Med. 23 (1997) 996-1001.

[54] L. Soltes, R. Mendichi, G. Kogan, J. Schiller, M. Stankovska, J. Arnhold, Degradative action of reactive oxygen species on hyaluronan, Biomacromolecules 7 (2006) 659-668.

[55] C. Fieber, P. Baumann, R. Vallon, C. Termeer, J.C. Simon, M. Hofmann, P. Angel, P. Herrlich, J.P. Sleeman, Hyaluronan-oligosaccharide-induced transcription of metalloproteases, J. Cell Sci. 117 (2004) 359-367.

[56] V. Voelcker, C. Gebhardt, M. Averbeck, A. Saalbach, V. Wolf, F. Weih, J. Sleeman, U. Anderegg, J. Simon, Hyaluronan fragments induce cytokine and metalloprotease upregulation in human melanoma cells in part by signalling via TLR4, Exp. Dermatol. 17 (2008) 100-107.

[57] C.M. McKee, M.B. Penno, M. Cowman, M.D. Burdick, R.M. Strieter, C. Bao, P.W. Noble, Hyaluronan (HA) fragments induce chemokine gene expression in alveolar macrophages. The role of HA size and CD44, J. Clin. Invest. 98 (1996) 2403-2413.

[58] Y. Takahashi, L. Li, M. Kamiryo, T. Asteriou, A. Moustakas, H. Yamashita, P. Heldin, Hyaluronan fragments induce endothelial cell differentiation in a CD44- and CXCL1/GRO1-dependent manner, J. Biol. Chem. 280 (2005) 24195-24204.

[59] K.R. Taylor, J.M. Trowbridge, J.A. Rudisill, C.C. Termeer, J.C. Simon, R.L. Gallo, Hyaluronan fragments stimulate endothelial recognition of injury through TLR4, J. Biol. Chem. 279 (2004) 17079-17084.

[60] H. Saari, Y.T. Konttinen, Determination of synovial fluid hyaluronate concentration and polymerisation by high performance liquid chromatography, Ann. Rheum. Dis. 48 (1989) 565-570.

[61] J. Iijima, K. Konno, N. Itano, Inflammatory alterations of the extracellular matrix in the tumor microenvironment, Cancers (Basel) 3 (2011) 3189-3205.

[62] B.P. Toole, Hyaluronan: from extracellular glue to pericellular cue, Nat. Rev. Cancer 4 (2004) 528-539.

[63] M.R. Horton, C.M. McKee, C. Bao, F. Liao, J.M. Farber, J. Hodge-DuFour, E. Pure, B.L. Oliver, T.M. Wright, P.W. Noble, Hyaluronan fragments synergize with interferon-gamma to induce the $\mathrm{C}-\mathrm{X}-\mathrm{C}$ chemokines mig and interferon-inducible protein-10 in mouse macrophages, J. Biol. Chem. 273 (1998) 35088-35094.

[64] M.R. Horton, M.A. Olman, P.W. Noble, Hyaluronan fragments induce plasminogen activator inhibitor- 1 and inhibit urokinase activity in mouse alveolar macrophages: a potential mechanism for impaired fibrinolytic activity in acute lung injury, Chest 116 (1999) $17 \mathrm{~S}$.

[65] P.W. Noble, C.M. McKee, M. Cowman, H.S. Shin, Hyaluronan fragments activate an NF-kappa B/I-kappa B alpha autoregulatory loop in murine macrophages, J. Exp. Med. 183 (1996) 2373-2378.

[66] R. Deed, P. Rooney, P. Kumar, J.D. Norton, J. Smith, A.J. Freemont, S. Kumar, Early-response gene signalling is induced by angiogenic oligosaccharides of hyaluronan in endothelial cells. Inhibition by non-angiogenic, high-molecularweight hyaluronan, Int. J. Cancer 71 (1997) 251-256.

[67] P. Rooney, M. Wang, P. Kumar, S. Kumar, Angiogenic oligosaccharides of hyaluronan enhance the production of collagens by endothelial cells, J. Cell Sci. 105 (Pt 1) (1993) 213-218.

[68] A. Aruffo, I. Stamenkovic, M. Melnick, C.B. Underhill, B. Seed, CD44 is the principal cell surface receptor for hyaluronate, Cell 61 (1990) 1303-1313.

[69] L. Sherman, J. Sleeman, P. Herrlich, H. Ponta, Hyaluronate receptors: key players in growth, differentiation, migration and tumor progression, Curr. Opin. Cell Biol. 6 (1994) 726-733.

[70] J. Lesley, R. Hyman, P.W. Kincade, CD44 and its interaction with extracellular matrix, Adv. Immunol. 54 (1993) 271-335.

[71] R.S. Peterson, R.A. Andhare, K.T. Rousche, W. Knudson, W. Wang, J.B. Grossfield, R.O. Thomas, R.E. Hollingsworth, C.B. Knudson, CD44 modulates Smad1 activation in the BMP-7 signaling pathway, J. Cell Biol. 166 (2004) 1081-1091.

[72] Q. Yu, I. Stamenkovic, Cell surface-localized matrix metalloproteinase-9 proteolytically activates TGF-beta and promotes tumor invasion and angiogenesis, Genes Dev. 14 (2000) 163-176.

[73] K. Svee, J. White, P. Vaillant, J. Jessurun, U. Roongta, M. Krumwiede, D. Johnson, C. Henke, Acute lung injury fibroblast migration and invasion of a fibrin matrix is mediated by CD44, J. Clin. Invest. 98 (1996) 1713-1727.

[74] D. Vigetti, M. Viola, E. Karousou, M. Rizzi, P. Moretto, A. Genasetti, M. Clerici, V.C. Hascall, G. De Luca, A. Passi, Hyaluronan-CD44-ERK1/2 regulate human aortic smooth muscle cell motility during aging, J. Biol. Chem. 283 (2008) 4448-4458.

[75] L.Y. Bourguignon, E. Gilad, A. Brightman, F. Diedrich, P. Singleton, HyaluronanCD44 interaction with leukemia-associated RhoGEF and epidermal growth factor receptor promotes Rho/Ras co-activation, phospholipase C epsilon-Ca2 + signaling, and cytoskeleton modification in head and neck squamous cell carcinoma cells, J. Biol. Chem. 281 (2006) 14026-14040.

[76] L. Li, C.H. Heldin, P. Heldin, Inhibition of platelet-derived growth factor-BB-induced receptor activation and fibroblast migration by hyaluronan activation of CD44, J. Biol. Chem. 281 (2006) 26512-26519.

[77] G. Kaya, I. Rodriguez, J.L. Jorcano, P. Vassalli, I. Stamenkovic, Selective suppression of CD44 in keratinocytes of mice bearing an antisense CD44 transgene driven by a tissue-specific promoter disrupts hyaluronate metabolism in the skin and impairs keratinocyte proliferation, Genes Dev. 11 (1997) 996-1007.

[78] P. Teder, R.W. Vandivier, D. Jiang, J. Liang, L. Cohn, E. Pure, P.M. Henson, P.W. Noble, Resolution of lung inflammation by CD44, Science 296 (2002) 155-158.

[79] J. Liang, D. Jiang, J. Griffith, S. Yu, J. Fan, X. Zhao, R. Bucala, P.W. Noble, CD44 is a negative regulator of acute pulmonary inflammation and lipopolysaccharide-TLR signaling in mouse macrophages, J. Immunol. 178 (2007) 2469-2475.

[80] J. Muto, K. Yamasaki, K.R. Taylor, R.L. Gallo, Engagement of CD44 by hyaluronan suppresses TLR4 signaling and the septic response to LPS, Mol. Immunol. 47 (2009) 449-456.
[81] R.A. Clark, F. Lin, D. Greiling, J. An, J.R. Couchman, Fibroblast invasive migration into fibronectin/fibrin gels requires a previously uncharacterized dermatan sulfate-CD44 proteoglycan, J. Invest. Dermatol. 122 (2004) 266-277.

[82] G. Tzircotis, R.F. Thorne, C.M. Isacke, Chemotaxis towards hyaluronan is dependent on CD44 expression and modulated by cell type variation in CD44-hyaluronan binding, J. Cell Sci. 118 (2005) 5119-5128.

[83] P.S. Acharya, S. Majumdar, M. Jacob, J. Hayden, P. Mrass, W. Weninger, R.K. Assoian, E. Pure, Fibroblast migration is mediated by CD44-dependent TGF beta activation, J. Cell Sci. 121 (2008) 1393-1402.

[84] C. Hardwick, K. Hoare, R. Owens, H.P. Hohn, M. Hook, D. Moore, V. Cripps, L. Austen, D.M. Nance, E.A. Turley, Molecular cloning of a novel hyaluronan receptor that mediates tumor cell motility, J. Cell Biol. 117 (1992) 1343-1350.

[85] B. Yang, L. Zhang, E.A. Turley, Identification of two hyaluronan-binding domains in the hyaluronan receptor RHAMM, J. Biol. Chem. 268 (1993) 8617-8623.

[86] R.C. Savani, G. Cao, P.M. Pooler, A. Zaman, Z. Zhou, H.M. DeLisser, Differential involvement of the hyaluronan (HA) receptors CD44 and receptor for HA-mediated motility in endothelial cell function and angiogenesis, J. Biol. Chem. 276 (2001) 36770-36778.

[87] J. Entwistle, C.L. Hall, E.A. Turley, HA receptors: regulators of signalling to the cytoskeleton, J. Cell. Biochem. 61 (1996) 569-577.

[88] E.A. Turley, P.W. Noble, L.Y. Bourguignon, Signaling properties of hyaluronan receptors, J. Biol. Chem. 277 (2002) 4589-4592.

[89] P.G. Telmer, C. Tolg, J.B. McCarthy, E.A. Turley, How does a protein with dual mitotic spindle and extracellular matrix receptor functions affect tumor susceptibility and progression? Commun. Integr. Biol. 4 (2011) 182-185.

[90] D. Nikitovic, K. Kouvidi, N.K. Karamanos, G.N. Tzanakakis, The roles of hyaluronan/ RHAMM/CD44 and their respective interactions along the insidious pathways of fibrosarcoma progression, Biomed. Res. Int. 2013 (2013) 929531.

[91] K. Kouvidi, A. Berdiaki, D. Nikitovic, P. Katonis, N. Afratis, V.C. Hascall, N.K Karamanos, G.N. Tzanakakis, Role of receptor for hyaluronic acid-mediated motility (RHAMM) in low molecular weight hyaluronan (LMWHA)-mediated fibrosarcoma cell adhesion, J. Biol. Chem. 286 (2011) 38509-38520.

[92] C.L. Hall, B. Yang, X. Yang, S. Zhang, M. Turley, S. Samuel, L.A. Lange, C. Wang, G.D. Curpen, R.C. Savani, A.H. Greenberg, E.A. Turley, Overexpression of the hyaluronan receptor RHAMM is transforming and is also required for H-ras transformation, Cell 82 (1995) 19-26.

[93] M. Hofmann, V. Assmann, C. Fieber, J.P. Sleeman, J. Moll, H. Ponta, I.R. Hart, P. Herrlich, Problems with RHAMM: a new link between surface adhesion and oncogenesis? Cell 95 (1998) 591-592 (author reply 592-593).

[94] C. Tolg, S.R. Hamilton, K.A. Nakrieko, F. Kooshesh, P. Walton, J.B. McCarthy, M.J Bissell, E.A. Turley, Rhamm-/- fibroblasts are defective in CD44-mediated ERK1,2 motogenic signaling, leading to defective skin wound repair, J. Cell Biol. 175 (2006) 1017-1028.

[95] A. Zaman, Z. Cui, J.P. Foley, H. Zhao, P.C. Grimm, H.M. Delisser, R.C. Savani, Expression and role of the hyaluronan receptor RHAMM in inflammation after bleomycin injury, Am. J. Respir. Cell Mol. Biol. 33 (2005) 447-454.

[96] C. Tolg, R. Poon, R. Fodde, E.A. Turley, B.A. Alman, Genetic deletion of receptor for hyaluronan-mediated motility (Rhamm) attenuates the formation of aggressive fibromatosis (desmoid tumor), Oncogene 22 (2003) 6873-6882.

[97] E.N. Harris, S.V. Kyosseva, J.A. Weigel, P.H. Weigel, Expression, processing, and glycosaminoglycan binding activity of the recombinant human 315-kDa hyaluronic acid receptor for endocytosis (HARE), J. Biol. Chem. 282 (2007) 2785-2797.

[98] B. Zhou, J.A. Weigel, L. Fauss, P.H. Weigel, Identification of the hyaluronan receptor for endocytosis (HARE), J. Biol. Chem. 275 (2000) 37733-37741.

[99] H. Nonaka, M. Tanaka, K. Suzuki, A. Miyajima, Development of murine hepatic sinusoidal endothelial cells characterized by the expression of hyaluronan receptors, Dev. Dyn. 236 (2007) 2258-2267.

[100] O. Politz, A. Gratchev, P.A. McCourt, K. Schledzewski, P. Guillot, S. Johansson, G. Svineng, P. Franke, C. Kannicht, J. Kzhyshkowska, P. Longati, F.W. Velten, S. Johansson, S. Goerdt, Stabilin-1 and -2 constitute a novel family of fasciclin-like hyaluronan receptor homologues, Biochem. J. 362 (2002) 155-164.

[101] C.T. McGary, J.A. Weigel, P.H. Weigel, Study of hyaluronan-binding proteins and receptors using iodinated hyaluronan derivatives, Methods Enzymol. 363 (2003) 354-365.

[102] B. Zhou, J.A. Weigel, A. Saxena, P.H. Weigel, Molecular cloning and functional expression of the rat $175-\mathrm{kDa}$ hyaluronan receptor for endocytosis, Mol. Biol Cell 13 (2002) 2853-2868.

[103] M.S. Pandey, B.A. Baggenstoss, J. Washburn, E.N. Harris, P.H. Weigel, The hyaluronan receptor for endocytosis (HARE) activates NF-kappaB-mediated gene expression in response to $40-400-\mathrm{kDa}$, but not smaller or larger, hyaluronans, J. Biol. Chem. 288 (2013) 14068-14079.

[104] S. Banerji, J. Ni, S.X. Wang, S. Clasper, J. Su, R. Tammi, M. Jones, D.G. Jackson, LYVE-1, a new homologue of the CD44 glycoprotein, is a lymph-specific receptor for hyaluronan, J. Cell Biol. 144 (1999) 789-801.

[105] R. Prevo, S. Banerji, D.J. Ferguson, S. Clasper, D.G. Jackson, Mouse LYVE-1 is an endocytic receptor for hyaluronan in lymphatic endothelium, J. Biol. Chem. 276 (2001) 19420-19430.

[106] C. Mouta Carreira, S.M. Nasser, E. di Tomaso, T.P. Padera, Y. Boucher, S.I. Tomarev, R.K. Jain, LYVE-1 is not restricted to the lymph vessels: expression in normal liver blood sinusoids and down-regulation in human liver cancer and cirrhosis Cancer Res. 61 (2001) 8079-8084.

[107] T. Wrobel, P. Dziegiel, G. Mazur, M. Zabel, K. Kuliczkowski, A. Szuba, LYVE-1 expression on high endothelial venules (HEVs) of lymph nodes, Lymphology 38 (2005) 107-110.

[108] Y. Akishima, K. Ito, L. Zhang, Y. Ishikawa, H. Orikasa, H. Kiguchi, Y. Akasaka, K Komiyama, T. Ishii, Immunohistochemical detection of human small lymphatic 
vessels under normal and pathological conditions using the LYVE-1 antibody, Virchows Arch. 444 (2004) 153-157.

[109] S.M. Maula, M. Luukkaa, R. Grenman, D. Jackson, S. Jalkanen, R. Ristamaki, Intratumoral lymphatics are essential for the metastatic spread and prognosis in squamous cell carcinomas of the head and neck region, Cancer Res. 63 (2003) 1920-1926.

[110] L.A. Johnson, R. Prevo, S. Clasper, D.G. Jackson, Inflammation-induced uptake and degradation of the lymphatic endothelial hyaluronan receptor LYVE-1, J. Biol. Chem. 282 (2007) 33671-33680.

[111] K. Schledzewski, M. Falkowski, G. Moldenhauer, P. Metharom, J. Kzhyshkowska, R Ganss, A. Demory, B. Falkowska-Hansen, H. Kurzen, S. Ugurel, G. Geginat, B. Arnold, $\mathrm{S}$. Goerdt, Lymphatic endothelium-specific hyaluronan receptor LYVE-1 is expressed by stabilin- $1+, \mathrm{F} 4 / 80+, \mathrm{CD} 11 \mathrm{~b}+$ macrophages in malignant tumours and wound healing tissue in vivo and in bone marrow cultures in vitro: implications for the assessment of lymphangiogenesis, J. Pathol. 209 (2006) 67-77.

[112] N.W. Gale, R. Prevo, J. Espinosa, D.J. Ferguson, M.G. Dominguez, G.D. Yancopoulos, G. Thurston, D.G. Jackson, Normal lymphatic development and function in mice deficient for the lymphatic hyaluronan receptor LYVE-1, Mol. Cell. Biol. 27 (2007) 595-604.

[113] L.A. Johnson, S. Clasper, A.P. Holt, P.F. Lalor, D. Baban, D.G. Jackson, An inflammation-induced mechanism for leukocyte transmigration across lymphatic vessel endothelium, J. Exp. Med. 203 (2006) 2763-2777.

[114] N. Platonova, G. Miquel, B. Regenfuss, S. Taouji, C. Cursiefen, E. Chevet, A. Bikfalvi, Evidence for the interaction of fibroblast growth factor- 2 with the lymphatic endothelial cell marker LYVE-1, Blood 121 (2013) 1229-1237.

[115] W.H. Hou, I.H. Liu, C.C. Tsai, F.E. Johnson, S.S. Huang, J.S. Huang, CRSBP-1/ LYVE-1 ligands disrupt lymphatic intercellular adhesion by inducing tyrosine phosphorylation and internalization of VE-cadherin, J. Cell Sci. 124 (2011) 1231-1244.

[116] A. Aderem, R.J. Ulevitch, Toll-like receptors in the induction of the innate immune response, Nature 406 (2000) 782-787.

[117] K. Takeda, T. Kaisho, S. Akira, Toll-like receptors, Annu. Rev. Immunol. 21 (2003) 335-376.

[118] O. Takeuchi, K. Hoshino, T. Kawai, H. Sanjo, H. Takada, T. Ogawa, K. Takeda, S. Akira, Differential roles of TLR2 and TLR4 in recognition of gram-negative and grampositive bacterial cell wall components, Immunity 11 (1999) 443-451.

[119] B.M. Tesar, D. Jiang, J. Liang, S.M. Palmer, P.W. Noble, D.R. Goldstein, The role of hyaluronan degradation products as innate alloimmune agonists, Am. J. Transplant. 6 (2006) 2622-2635.

[120] C. del Fresno, K. Otero, L. Gomez-Garcia, M.C. Gonzalez-Leon, L. Soler-Ranger, P. Fuentes-Prior, P. Escoll, R. Baos, L. Caveda, F. Garcia, F. Arnalich, E. Lopez-Collazo, Tumor cells deactivate human monocytes by up-regulating IL-1 receptor associated kinase-M expression via CD44 and TLR4, J. Immunol. 174 (2005) 3032-3040.

[121] E.J. Chang, H.J. Kim, J. Ha, H.J. Kim, J. Ryu, K.H. Park, U.H. Kim, Z.H. Lee, H.M. Kim, D.E. Fisher, H.H. Kim, Hyaluronan inhibits osteoclast differentiation via Toll-like receptor 4, J. Cell Sci. 120 (2007) 166-176.

[122] S. Rakoff-Nahoum, J. Paglino, F. Eslami-Varzaneh, S. Edberg, R. Medzhitov, Recognition of commensal microflora by toll-like receptors is required for intestinal homeostasis, Cell 118 (2004) 229-241.

[123] S. Gariboldi, M. Palazzo, L. Zanobbio, S. Selleri, M. Sommariva, L. Sfondrini, S. Cavicchini, A. Balsari, C. Rumio, Low molecular weight hyaluronic acid increases the self-defense of skin epithelium by induction of beta-defensin 2 via TLR2 and TLR4, J. Immunol. 181 (2008) 2103-2110. 